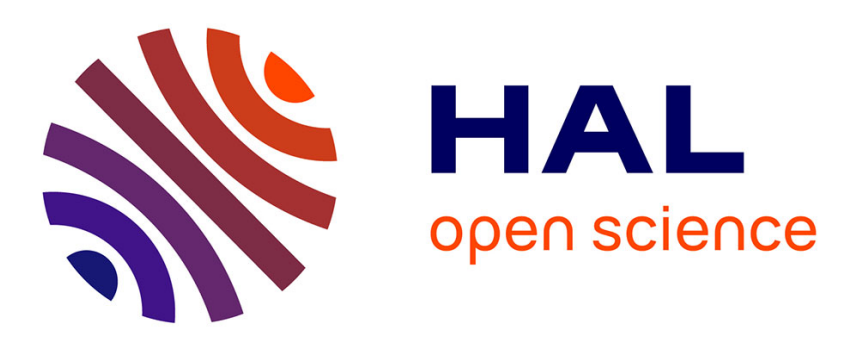

\title{
Synthesis of a Tunable Impedance Inverter Based on Variable Position of Capacitive-Loads
}

\author{
Gaëtan Prigent, Pedro Rynkiewicz, Anne-Laure Franc
}

\section{To cite this version:}

Gaëtan Prigent, Pedro Rynkiewicz, Anne-Laure Franc. Synthesis of a Tunable Impedance Inverter Based on Variable Position of Capacitive-Loads. Asia Pacific Microwave Conference (APMC), Dec 2019, Singapour, Singapore. hal-02456499

\section{HAL Id: hal-02456499 \\ https://hal.science/hal-02456499}

Submitted on 27 Jan 2020

HAL is a multi-disciplinary open access archive for the deposit and dissemination of scientific research documents, whether they are published or not. The documents may come from teaching and research institutions in France or abroad, or from public or private research centers.
L'archive ouverte pluridisciplinaire HAL, est destinée au dépôt et à la diffusion de documents scientifiques de niveau recherche, publiés ou non, émanant des établissements d'enseignement et de recherche français ou étrangers, des laboratoires publics ou privés. 


\section{Synthesis of a Tunable Impedance Inverter Based on Variable Position of Capacitive-Loads}

\author{
Gaëtan Prigent \\ LAAS-CNRS \\ University of Toulouse, CNRS, INP \\ Toulouse, France \\ gaetan.prigent@laas.fr
}

\author{
Pedro Rynkiewicz \\ LAPLACE \\ University of Toulouse, INP \\ Toulouse, France \\ Pedro.rynkiewicz@laplace.univ-tlse.fr
}

\author{
Anne-Laure Franc \\ LAPLACE \\ University of Toulouse, INP \\ Toulouse, France \\ anne-laure.franc@laplace.univ-tlse.fr
}

\begin{abstract}
This work presents a topology to meet the demand of tunable quarter-wavelength impedance inverters. The proposed solution lies in a transmission line loaded by capacitors whose positions are variable. The associated synthesis is proposed and leads to the possibility of producing a quarterwave inverter operating at two different frequencies and with two characteristic impedances that can be optimized thanks to the degree of freedom provided by the position of the capacitors.
\end{abstract}

Keywords-Impedance inverter, tunable filters, synthesis.

\section{INTRODUCTION}

Considering the spectrum spreading for embedded applications and the necessity of flexible data flows depending on the needs of end-users as well as the need for very high frequency multifunctional systems, the tunability appears as a key issue for low-cost integrated systems. Indeed, many functions only differ from center frequency or bandwidth [1]. Therefore, by promoting the design of tunable devices that can address all or part of the operating bands one can dramatically reduce the size, cost and complexity of the system. Moreover, the need for high capacity links the use of high frequency bands is required, notably with the imminent arrival of $5 \mathrm{G}$ systems [2]. Within this context, the use of high-quality passive circuits is a key issue; they have to meet the system requirements in terms of selectivity and losses while maintaining their performance whatever the tunability. Unfortunately, for tunable functions the electrical performance are degraded with the tuning range. Thereby, one has to provide systems robust to the frequency change.

Among the passive functions filters are one of the most sensitive components, especially tunable filters. Most of planar filter topologies are composed of resonators and inverters whose characteristics, i.e. electrical lengths and impedance, control both center frequency and bandwidth. Fundamental components in the design of filters in millimeter frequency range are transmission lines. In the case of tunable filters, the center frequency can be controlled by changing the electrical length. However, the more the center frequency is far the nominal frequency, the more the filter response is degraded, especially the in-band return loss which is linked to impedance of the transmission line. It is therefore important to provide transmission lines whose electrical properties can be modified to fit the requirement in terms of frequency shift.
Although much work has been done to modify the electrical length of the line [3], few results are available on the characteristic impedance variation. The solution proposed in this work is to move capacitors along the transmission line in order to modify the equivalent impedance without affecting the electrical length. The displacement of series varactors was introduced in [4] in order to produce a tunable resonator in central frequency and in bandwidth, but it was not treated from a transmission line point of view. So as to improve the mastery in design, essential in millimeter- and sub-millimeterbands, a synthesis in proposed for dual-band quarter wavelength inverter with tunable impedance.

\section{CAPACITIVE LOADING WITH VARIABLE POSITION}

\section{A. Transmission line topology}

In this part, a transmission line with a characteristic impedance of $Z_{c}$ is symmetrically loaded with capacitors located at a variable position defined by $P$ (Fig. 1).

When $\mathrm{P}$ is 0 , the two capacitors are overlapped on the center of the transmission line and when $P=1$, they are arranged at each end. This variation of position is modeled by an electrical length of line dependent on $P$ according to (1) and (2) where $\theta_{H}=2 \cdot\left(\theta_{P}+\theta_{1-P}\right)$ is the electric length of the unloaded transmission line defined at the nominal highest frequency $f_{H}$.

$$
\begin{aligned}
& \theta_{1-P}=(1-P) \cdot \theta_{H} / 2 \\
& \theta_{P}=P \cdot \theta_{H} / 2
\end{aligned}
$$

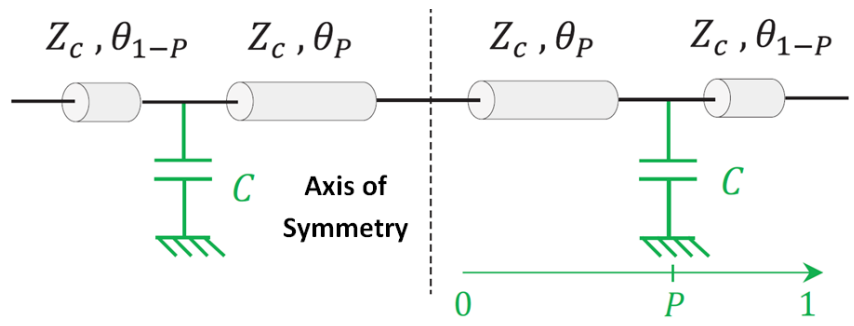

Fig. 1 Topology of the capacitive-loaded transmission line with variable position $\mathrm{P}$. 
The coefficient of the equivalent chain matrix ( $A B C D e q)$ of the loaded transmission line are given in APPENDIX 1. At a given low frequency $f_{L}$, with lossless transmission lines, this matrix is then determined by (4)-(7), with $C_{N}$ the normalized impedance such as:

$$
C_{N}=2 \pi \cdot f_{L} \cdot C \cdot Z_{c}
$$

From the chain matrix, the equivalent electrical properties of the loaded line can be obtained at any frequency $f_{L}$.

\section{B. Application to impedance inverters}

In order to focus on the application of a tunable quarterwavelength inverter, the frequencies $f_{H}$ and $f_{L}$ are the two operating frequencies for which the line must have a behavior comparable to transmission line with electrical length of $\lambda / 4$. The unloaded transmission line is quarter wavelength at $f_{H}\left(\theta_{H}\right.$ $=90^{\circ}$ ).

The equivalent electrical lengths of the loaded line have to verify $\theta_{e q}=90^{\circ}$ at $f_{L}$, i.e. a chain matrix of the form (7).

$$
[A B C D]_{e q}=\left[\begin{array}{cc}
A_{e q} & B_{e q} \\
C_{e q} & D_{e q}
\end{array}\right]=\left[\begin{array}{cc}
0 & j Z_{e q} \\
j Y_{e q} & 0
\end{array}\right]
$$

Determining the capacitance value to reach an equivalent electrical length of $90^{\circ}$ requires solving $A_{e q}=0$ at $f_{L}$. This calculation leads to a second order equation in $C_{N}$ and thus has two roots. The solution chosen is (8) because it vanishes for $\theta_{I}=90^{\circ}$ at $f_{H}$. This means that no capacitor is needed to retrieve an impedance inverter behavior at $f_{H}$, so the topology is simply that of the unloaded line.

$$
\begin{aligned}
C_{N} & =\frac{\sin \theta_{L}-\cos \theta_{L} \cdot \sqrt{2 \sin ^{2} P \theta_{L}+\tan ^{2} \theta_{L}-\sin 2 P \theta_{L} \cdot \tan \theta_{L}}}{\sin \theta_{L} \cdot \sin P \theta_{L} \cdot \cos P \theta_{L}-\cos \theta_{L} \cdot \sin ^{2} P \theta_{L}} \\
\theta_{L} & =\frac{\pi}{2} \cdot \frac{f_{L}}{f_{H}}
\end{aligned}
$$

Finally, the equivalent impedance can be recalculated from the chain matrix by applying the following relation:

$$
\left.Z_{e q}\right|_{\theta=\theta_{L}}=\sqrt{\frac{B_{e q}}{C_{e q}}}
$$

\section{Results}

Fig. 2 presents the equivalent impedance variation with the capacitor position $P$. The unloaded transmission line is quarter wavelength at $f_{H}=100 \mathrm{GHz}$. The impedance of the transmission line depends on the application, in the study case it is considered to be $50-\Omega$. Three frequencies $\left(f_{L}\right)$ are investigated for capacitive-loaded transmission lines: $40 \mathrm{GHz}$,
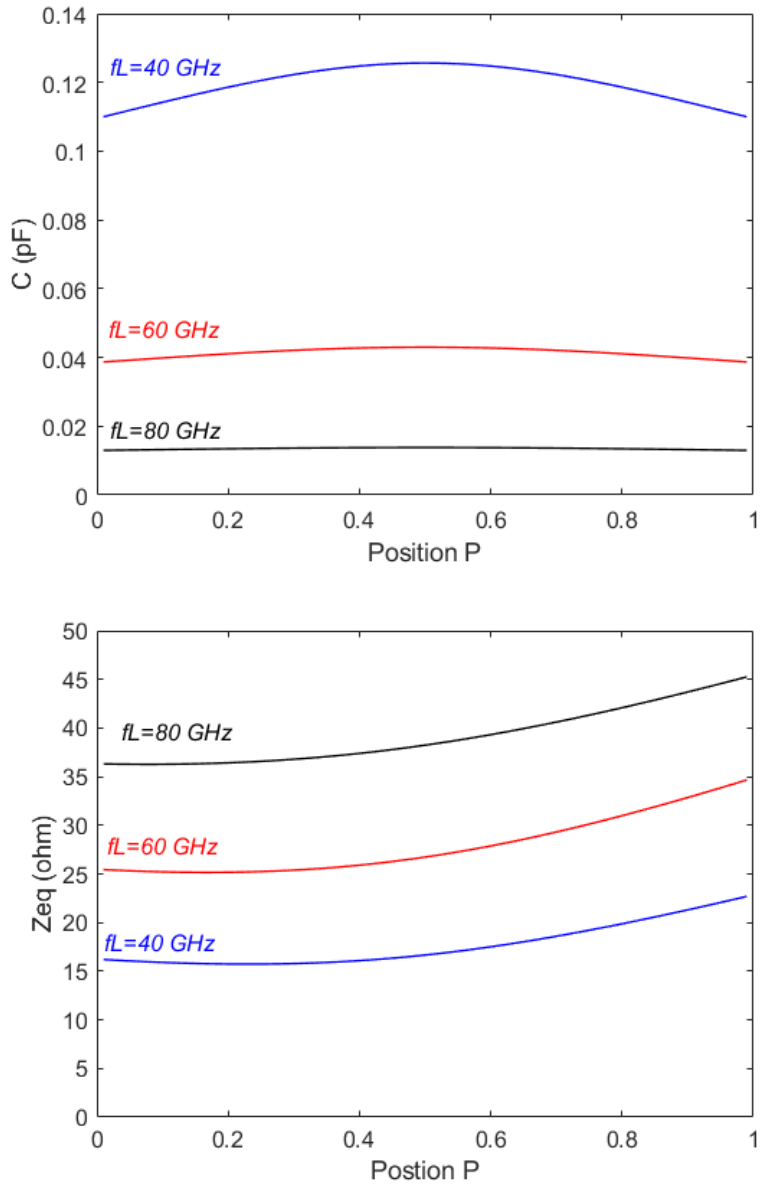

Fig. 2 Variations of the capacitor value and equivalent impedance of quarter wavelength inverter as a function of the capacitor position $P$.

$60 \mathrm{GHz}$ and $80 \mathrm{GHz}$. Depending on its position $(P)$, the capacitor value is modified following equation (8) to ensure quarter-wavelength behavior at $f_{L}$. For instance, the C-loaded transmission line behaves as a $50-\Omega$ quarter wavelength transmission line at $100 \mathrm{GHz}$ whereas at $f_{L}=40 \mathrm{GHz}$ it has the behavior of a quarter wavelength transmission line with impedance range of $[16-22.7]-\Omega$ depending on the capacitor value i.e. its position. Thereby, the degree-of-freedom introduced by the C-loaded transmission line allows designing dual-band impedance inverters with continuously variable impedance. This is fundamental in the design of many functions and especially on tunable filters. Indeed in numerous filter topologies the bandwidth and return loss level are controlled by impedance values. Thereby, as one can impose impedance while keeping constant the electrical length, the mastering in the design of passive devices is improved.

APPENDIX 1: EQUATIONS FOR C-LOADED TRANSMISSION-LINE DESCRIBED IN FIG. 1

$$
\begin{aligned}
& A_{e q}=D_{e q}=\cos \theta-C_{N} \cdot \sin \theta+\left\{C_{N}^{2} \cdot \sin [2 \cdot(1-\mathrm{P}) \cdot \theta] \cdot \sin (2 \cdot \mathrm{P} \cdot \theta)\right\} / 2 \\
& B_{e q}=j \cdot Z_{c} \cdot\left\{\sin \theta+C_{N} \cdot[\cos \theta-\cos (2 \cdot \mathrm{P} \cdot \theta)]+\frac{C_{N}^{2} \cdot \sin (2 \cdot \mathrm{P} \cdot \theta) \cdot \sin ^{2}[2 \cdot(1-\mathrm{P}) \cdot \theta]}{2}\right\} \\
& C_{e q}=j \cdot\left\{\sin \theta+C_{N} \cdot[\cos \theta+\cos (2 \cdot \mathrm{P} \cdot \theta)]-\frac{C_{N}^{2} \cdot \sin (2 \cdot \mathrm{P} \cdot \theta) \cdot \sin ^{2}[2 \cdot(1-\mathrm{P}) \cdot \theta]}{2}\right\} / Z_{C}
\end{aligned}
$$




\section{III.APPLICATION TO BANDPASS FILTER}

For the sake of illustration of the interest of such an inverter synthesis, a ring-based bandpass filter is designed [5]. It is based on the use of two pairs of quarter wavelength transmission lines with different impedances $Z_{1}$ and $Z_{2}$ (Fig. 3). The synthesis of the unloaded nominal filter was given in [5]. The filter bandwidth is ruled by the impedance ratio between $Z_{1}$ and $Z_{2}$. The nominal frequency $f_{H}$ is set to $60 \mathrm{GHz}$ and the final frequency $f_{L}=45 \mathrm{GHz}$. The capacitor $\left(C_{a 1}, C_{a 2}\right)$ values are calculated according to equation (8). As depicted in Figs. 4-5 the use of continuously tunable impedance allows controlling the filter bandwidth while maintaining the center frequency and return loss level. The change of the capacitor position in the transmission line allows modifying the relative bandwidth from 15 to $20.8 \%$.

\section{IV.CONCLUSION}

The synthesis of quarter wavelength impedance inverters with tunable impedance wave proposed. It allows determining the value and position of capacitors to reach specification in terms of equivalent transmission line impedance while maintaining a $90^{\circ}$ phase-shift whatever the operating frequency. Thereby, the capacitive-loaded transmission line allows controlling its equivalent impedance while keeping constant its geometry (width and length), the impedance tunability being achieved changing the capacitor position. This concept was applied in the design of a ring bandpass filter which bandwidth is ruled by impedance ratio of quarter wavelength transmission lines. The filter bandwidth was controlled modifying the capacitor position while maintaining the center frequency and return loss which proves the efficiency of the proposed synthesis. Hence, this synthesis allows designing filters with double tunability: center frequency and bandwidth.

\section{REFERENCES}

1. G. M. Rebeiz, K. Entesari, I. C. Reines, S.-J. Park, M. A. Eltanani, A. Grichener, and R. Brown, "Tuning in to RF MEMS," IEEE Microwave magazine, vol. 10, no. 6, pp. 55-72, October 2009.

2. M. J. Marcus, "5G and "IMT for 2020 and beyond" [Spectrum Policy and Regulatory Issues]," IEEE Wireless Communications, vol. 22, no. 4, pp. 2-3, August 2015.

3. H. Issa, J. Duchamp, S. Abou-Chahine and P. Ferrari, "Loaded miniature transmission lines compatible with low cost substrates: Q-factor improvement," 40th European Microwave Conference, Paris, November 2010, pp. 1218-1221.

4. D. Lu, X. Tang, N. S. Barker and Y. Feng, "Single-Band and Switchable Dual-/Single-Band Tunable BPFs With Predefined Tuning Range, Bandwidth and Selectivity," IEEE Transactions on Microwave Theory and Techniques, vol. 66, no. 3, pp. 1215-1227, March 2018.

5. Rynkiewicz P, Franc A-L, Coccetti F, Wietstruck M, Wipf C, Tolunay Wipf S, Kaynak M, Prigent G., "Ring filter synthesis and its BiCMOS $60 \mathrm{GHz}$ implementation.", International Journal of Microwave and Wireless Technologies https://doi.org/10.1017/S1759078718000156

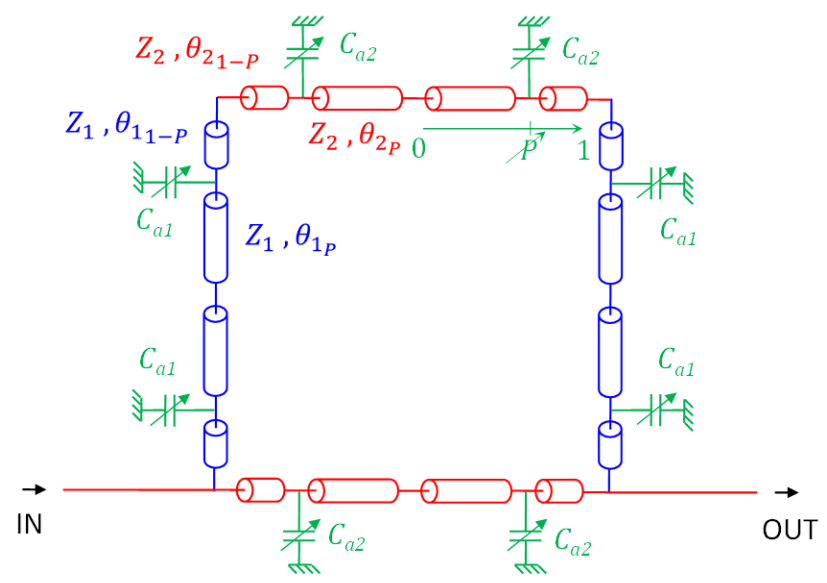

Fig. 3 Topology of the capacitive-loaded ring-based bandpass filter.

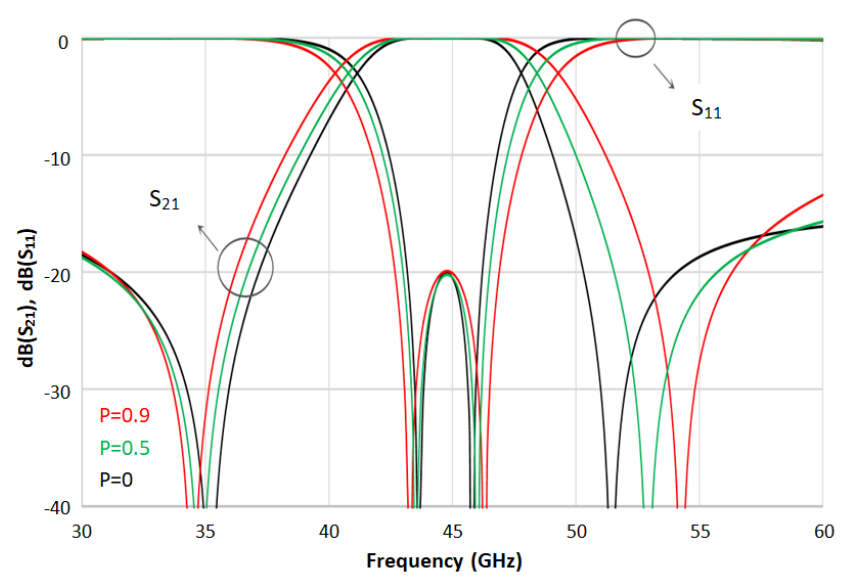

Fig. 4 Electrical response of the bandpass filter depending on the capacitor positions.

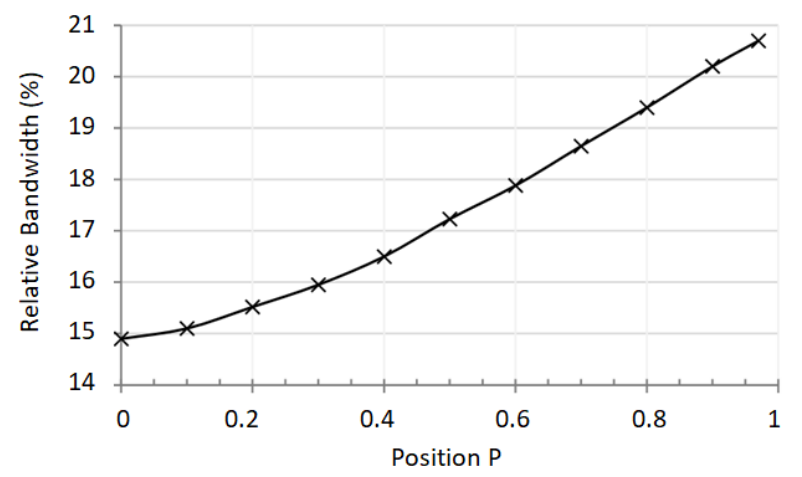

Fig. 5 Evolution of the filter bandwidth as a function of the capacitors position. 